\title{
Growth and public infrastructure
}

\author{
Article
}

Published Version

Hashimzade, N. and Myles, G. D. (2010) Growth and public infrastructure. Macroeconomics Dynamics, 14 (Supple). pp. 258-274. ISSN 1469-8056 doi: https://doi.org/10.1017/S1365100510000374 Available at https://centaur.reading.ac.uk/16926/

It is advisable to refer to the publisher's version if you intend to cite from the work. See Guidance on citing.

To link to this article DOI: http://dx.doi.org/10.1017/S1365100510000374

Publisher: Cambridge University Press

All outputs in CentAUR are protected by Intellectual Property Rights law, including copyright law. Copyright and IPR is retained by the creators or other copyright holders. Terms and conditions for use of this material are defined in the End User Agreement.

\section{www.reading.ac.uk/centaur}

\section{CentAUR}

Central Archive at the University of Reading

Reading's research outputs online 
Macroeconomic Dynamics, 1-17. Printed in the United States of America doi: $10.1017 /$ S1365100510000374

\title{
GROWTH AND PUBLIC INFRASTRUCTURE
}

\author{
Nigar HaShimzade \\ University of Reading \\ Gareth D. Myles \\ University of Exeter \\ and \\ Institute for Fiscal Studies
}

\begin{abstract}
The paper analyzes a multicountry extension of the Barro model of productive public expenditure. In the presence of positive infrastructural externalities between countries, the provision of infrastructure will be inefficiently low if countries do not coordinate. This provides a role for a supranational body, such as the European Union, to coordinate the policies of the individual governments. It is shown how intervention by a supranational body can raise welfare by internalizing the infrastructural externality. Infrastructural externalities increase the importance of tax policy in the growth process and distribute the benefits of taxation across countries.
\end{abstract}

Keywords: Public Infrastructure, Growth, Externalities

\section{INTRODUCTION}

One factor promoting endogenous growth is the supply of public infrastructure that complements the capital investments of the private sector. The importance of infrastructure is widely recognized, not least by the European Union (EU), which pursues an active program to support the investment activities of member states. The policy problem facing the EU is to ensure that member states undertake an efficient level of infrastructural expenditure that ensures the maximum rate of growth. The determination of this level has to take into account the full consequences of an infrastructure project for the EU, not just the direct benefits for the member state undertaking the investment. There are three significant issues that confront this policy program. First, infrastructural investment has significant spillovers across member states. Second, mobility of the tax base results in tax externalities between the member states, and between the member states and the EU. Third, the EU is faced with a decision on how to allocate support for infrastructural expenditure across the different member states. This interacts with the process of revenue-raising,

Thanks are due to Stephen Turnovsky, seminar participants in Birmingham, Cornell, Dublin, Keele, and Reading, and workshop participants in Brussels, Paris, PGPPE in Graz, and PET09 in Galway. Address correspondence to: Gareth D. Myles, Department of Economics, University of Exeter, Exeter EX6 8HT, UK; e-mail: gdmyles@ex.ac.uk. 
and with the extent to which the projects are financed jointly by the EU and member states.

Economic modeling of the impact of infrastructure on economic growth has focussed on the Barro (1990) model of public expenditure as a public input and its extensions [Chen et al. (2005) and Turnovsky (1999)]. This literature has identified the concept of an optimal level of expenditure, and has highlighted the deleterious effects of both inadequate and excessive expenditure. These are important insights, but they do not address the spillover issues that confront the EU. Infrastructural spillovers between member states can be positive, which occurs when improvements in infrastructure in one member state raise productivity in another, or they can be negative if they induce relocation of capital between member states. In either case, it is important that the consequences of spillovers be addressed for the role of productive public expenditure to be fully understood. Ignoring either form of spillover will result in an inefficient level and allocation of expenditure.

In this paper we construct a multicountry extension of the Barro model of productive public infrastructure in which the benefits of infrastructure spill over between countries. The spillover between countries is a form of externality that results in inefficient investment in infrastructure if countries act independently. If there are positive infrastructural externalities between countries, then the provision of infrastructure will be inefficiently low when countries do not coordinate policies. This gives a role to a supranational body, such as the EU, to act as a coordinator of the policies of individual governments. The financing of infrastructure in the Barro model is through a simple tax on output levied at the national level. The position in the EU is much more complex. Each member state levies national taxes. Part of the revenue from these taxes is retained by the member states; the remainder is remitted to and redistributed by the EU. In economic terms, if there is mobility of the tax base, then there are horizontal tax externalities between member states and a vertical tax externality between member states and the EU. These tax externalities have a key role in determining the growthmaximizing level of expenditure. We model a supranational body that intervenes by revenue-matching to counter the externality and obtain an increase in welfare. The infrastructural externality raises the importance of tax relative to a world without spillovers, because additional public infrastructure in one country can raise the growth rates in all. This holds if all countries are operating with less than the optimum level of infrastructure, as they will be in an equilibrium without policy intervention.

There are two distinct literatures that are related to this paper. The first is on the role of productive public expenditure in endogenous growth models. An extensive survey of the literature that has developed since Barro (1990) is provided by Irmen and Kuehnel (2009). One key result of the literature, which we exploit below, is that when public expenditure is a flow variable the economy will immediately settle onto a balanced growth path. In contrast, Futagami et al. (1993) analyze a model with public capital as a stock variable. In this case, the economy has 
transitional dynamics before reaching the balanced growth path. Optimal fiscal policy with a stock variable when the government expenditures are divided between capital and current expenditures is characterized in Gomez (2004) and in Tsoukis and Miller (2003). Marrero (2008) relates the level of investment in public capital to characteristics of the economy, including the elasticity of intertemporal substitution. A broader range of fiscal policies are studied in Turnovsky (2004) in a similar model. The central conclusion is that the transition period can be very lengthy, so policy can have a significant welfare effect along the transition path. We choose to represent the public good as a flow variable, so we do not need to address these transition issues. ${ }^{1}$ The common feature of the models just described is that they involve a single country, whereas our model involves infrastructural spillovers between countries. Iwamoto and Shibata (2008) also consider multiple countries with worldwide externalities. They show that the externalities provide a mechanism for equalizing growth rates across countries even if capital tax rates differ. The same result emerges when we introduce perfectly mobile capital.

The fact that the benefits of public expenditure spill over between countries gives a motive for countries to coordinate tax policies. This links our analysis to the literature on fiscal federalism. The static literature on fiscal federalism focuses on the benefits of decentralizing public good provision and the consequences of mobility for tax competition [see, for example, Boadway and Shah (2009)]. There is also a limited literature on fiscal federalism in growth settings. Brueckner (2006) shows how the tailoring of public good levels to local demand can promote growth in an overlapping-generations economy. The effect of mobility as a constraint on excessive taxation is studied by Rauscher (2005), but the results are ambiguous and depend on the elasticity of intertemporal substitution. This analysis is extended by Becker and Rauscher (2007) to a model with costly adjustment of capital. In this case there may be no balanced growth path. Hatfield (2006) contrasts the tax rate choices of decentralized and centralized governments. It is shown that a decentralized government chooses a tax rate that maximizes the growth rate, but underprovides public goods.

The paper is structured as follows. Section 2 analyzes a basic version of the endogenous growth model with a productive public input. Section 3 studies the role of a supranational body in coordinating the choices of individual countries when there is an infrastructural externality. The analysis is extended to accommodate the mobility of private capital in Section 4. Conclusions are given in Section 5.

\section{PUBLIC INFRASTRUCTURE}

Endogenous growth can occur when capital and labor are augmented by additional inputs in a production function that otherwise has nonincreasing returns to scale. One interesting case for understanding the link between government policy and growth is when the additional input is a public good or public infrastructure financed by taxation. The need for public infrastructure to support private capital in production provides a positive role for public expenditure and a direct mechanism 
through which policy can affect growth. The Barro (1990) model of productive public expenditure was the first to investigate the role of public infrastructure and permitted an analysis of the optimal level of public expenditure in an endogenous growth model.

With public infrastructure, the production function for the representative firm at time $t$ takes the form

$$
Y_{t}=A L_{t}^{1-\alpha} K_{t}^{\alpha} G_{t}^{1-\alpha},
$$

where $A$ is a positive constant and $G_{t}$ is the quantity of public infrastructure. The form of this production function ensures that there are constant returns to scale in labor, $L_{t}$, and private capital, $K_{t}$, for the firm given a fixed level of public infrastructure. Although returns to private capital are decreasing as the level of capital is increased for fixed levels of labor and public input, there are constant returns to scale in public input and private capital together. For a fixed level of $L_{t}$, this property of constant returns to scale in the other two inputs permits endogenous growth to occur.

We assume that government spending is funded from a tax levied on the private capital input. We further assume that public investment is a pure public good that fully depreciates after one period, so that $G_{t}$ is a flow variable. This allows us to focus on the balanced growth path equilibrium. The government runs a balanced budget in every period, so, with tax rate $\tau$, the level of public infrastructure in period $t$ is

$$
G_{t}=\tau K_{t}
$$

The firm belongs to a representative infinitely lived household whose preferences are from this point on described by an instantaneous utility function, $U_{t}=\ln \left(C_{t}\right)$. The household chooses the time path of the capital stock $\left\{K_{t}\right\}$ to maximize the infinite discounted stream of utility,

$$
\sum_{t=0}^{\infty} \beta^{t} \ln \left(C_{t}\right)
$$

subject to the sequence of intertemporal budget constraints

$$
Y_{t}=C_{t}+K_{t+1}-\left(1-\delta_{K}\right) K_{t}+\tau K_{t},
$$

where $\delta_{K} \geq 0$ is the rate of depreciation of private capital. The initial capital, $K_{0}$, is fixed and the household treats the tax rate, $\tau$, and the sequence of government infrastructure, $\left\{G_{t}\right\}$, as parametric. Assuming that $L_{t}$ is constant and setting $L_{t}=$ 1 , the objective of the household is

$$
\max _{\left\{K_{t}\right\}_{t=1}^{\infty}} U=\sum_{t=0}^{\infty} \beta^{t} \ln \left[A K_{t}^{\alpha} G_{t}^{1-\alpha}-K_{t+1}+\left(1-\delta_{K}-\tau\right) K_{t}\right] .
$$


Assuming an interior solution exists, the necessary conditions for the choice of $\left\{K_{t}\right\}_{t=0}^{\infty}$ can be solved to give

$$
\gamma_{t} \equiv \frac{C_{t}}{C_{t-1}}=\beta\left[\alpha A\left(\frac{G_{t}}{K_{t}}\right)^{1-\alpha}+1-\delta_{K}-\tau\right]-1, \quad t=1,2, \ldots
$$

The sequence $\left\{\gamma_{t}\right\}$ in (6) determines the rate of growth of consumption for the household in each period $t$ implied by the chosen time path of the capital stock. These conditions summarize the behavior of the private sector in the model.

The government chooses the tax rate, $\tau$, to maximize $U$, taking into account the effect on the decision of the household. The objective of the government is

$$
\max _{\{\tau\}} U=\sum_{t=0}^{\infty} \beta^{t} \ln \left(C_{t}\right)
$$

subject to (2) and (6). Substituting from (2) into (6), it follows that

$$
\gamma_{t}=\beta\left[\alpha A \tau^{1-\alpha}+1-\delta_{K}-\tau\right]-1 \equiv \gamma, \quad t=1,2, \ldots
$$

so the constant tax rate implies that the economy will be on a balanced growth path. Using the balanced growth path, the government objective can be written

$$
\max _{\{\tau\}} U=\frac{1}{1-\beta}\left[\ln \left(K_{0}\right)+\ln \left(A \tau^{1-\alpha}-\gamma-\delta_{K}-\tau\right)+\frac{\beta}{1-\beta} \ln (1+\gamma)\right] .
$$

The interior solution for the welfare-maximizing tax rate, $\tau_{w}$, along the balanced growth path is

$\frac{\beta}{1-\beta} \frac{1}{1+\gamma} \frac{d \gamma}{d \tau}+\frac{1}{A \tau_{w}^{1-\alpha}-\gamma-\delta_{K}-\tau_{w}}\left[(1-\alpha) A \tau_{w}^{-\alpha}-1-\frac{d \gamma}{d \tau}\right]=0$,

where $\gamma$ determined by (7).

The tax rate identified in (9) maximizes welfare. This tax rate does not maximize the rate of growth. From (7), the growth-maximizing tax rate is given by

$$
\tau_{m}=[\alpha(1-\alpha) A]^{1 / \alpha} .
$$

It is helpful to illustrate the nature of the solution for comparison with later results. We do this by calibrating the model and simulating the balanced growth path. For the model's parameters, we employ values that are broadly consistent with the calibration of business cycle and growth models; see, for example, Cooley and Prescott (1995). It can be seen in Figure 1 that (9) intersects (7) to the right of the maximum achievable growth rate, given the behavior of the household. The welfare-maximizing tax rate is given by $\tau_{w}=0.197$ and the growth rate by $\gamma_{w}=0.018$. The values for the growth-maximizing policy are $\tau_{m}=0.153$ and $\gamma_{m}=0.021$. It should be noted that neither of these policies achieves the first-best outcome for the economy, because the tax on capital is distortionary. 


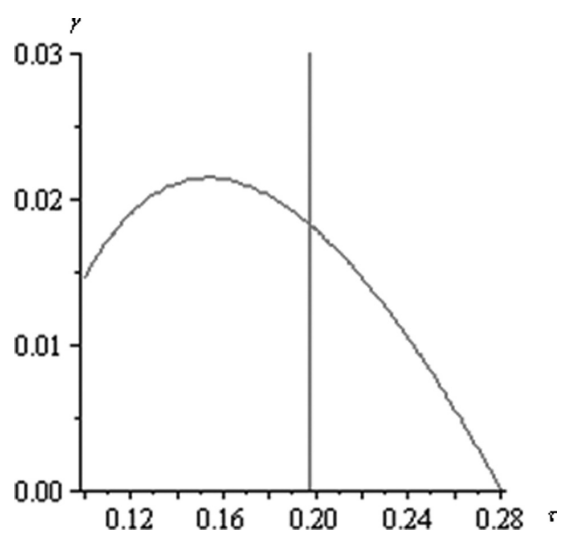

FIGURE 1. Single-country parameters: $\alpha=0.5, \beta=0.9, A=0.5, \delta_{K}=0.15$.

The decentralized outcome is inefficient, because the households, when making a decision on the level of private capital, do not internalize the externality associated with the provision of public capital. The source of inefficiency is the difference between the social marginal return on private capital and the after-tax private marginal product of capital. This inefficient choice of the household, in its turn, constrains the government in the choice of the tax rate.

\section{INFRASTRUCTURAL SPILLOVERS}

This section extends the model to a two-country economy in which production benefits from positive spillovers created by global infrastructure. The central observation is that independent optimization by countries does not internalize the externality resulting from the infrastructural spillover. This provides a role for a supranational body to coordinate the decisions of individual countries in order to secure an increase in welfare. We interpret the role of this central body as performing the function of the EU: it claims a share of the tax revenue of each country and then redistributes funds among countries.

We assume that there are two countries; one is called the "home" country and the other the "foreign" country. At time $t$, the level of output in the home country is given by

$$
Y_{t}=A K_{t}^{\alpha}\left(G_{t}^{1-\rho} \Gamma_{t}^{\rho}\right)^{1-\alpha}
$$

The measure of global infrastructure at time $t, \Gamma_{t}$, is defined as the total public investment in infrastructure, $\Gamma_{t}=G_{t}+\bar{G}_{t}$, where $\bar{G}_{t}$ is the public investment in infrastructure in the foreign country. The infrastructural externality is generated by the inclusion of the term $\bar{G}_{t}$. The interpretation is that both infrastructure within a country [the term involving $G_{t}$ in (10)] and the total level of infrastructure (the term involving $\Gamma_{t}$ ) are relevant. The production function in the foreign country is defined in the same way, and we assume that the parameters $\alpha$ and $\rho$ are the same for both countries. 
Extending (6), the necessary condition for the choice of the capital stock gives the following expression:

$$
\frac{C_{t}}{C_{t-1}} \equiv 1+\gamma_{t}=\beta\left[\alpha A\left(\frac{G_{t}}{K_{t}}\right)^{1-\alpha}\left(1+\frac{\bar{G}_{t}}{G_{t}}\right)^{\rho(1-\alpha)}+1-\delta_{K}-\tau\right] .
$$

Using (11) and the convention that $\gamma_{0}=0$, the objective of the government in the home country can be written as

$$
\max _{\{\tau\}} U=\sum_{t=0}^{\infty} \beta^{t} \ln \left(\Pi_{i=0}^{t}\left[1+\gamma_{i}\right] C_{0}\right),
$$

or, after some manipulation,

$$
\max _{\{\tau\}} U=\frac{1}{1-\beta}\left[\ln \left(C_{0}\right)+\sum_{t=0}^{\infty} \beta^{t} \ln \left(1+\gamma_{i}\right)\right] .
$$

The governments operate subject to the budget constraints $G_{t}=\tau K_{t}$ and $\bar{G}_{t}=$ $\bar{\tau} \bar{K}_{t}$, so the optimization in (12) is subject to the constraint

$$
\gamma_{t}=\beta\left[\alpha A \tau^{1-\alpha}\left(1+\frac{\bar{\tau} \bar{K}_{t}}{\tau K_{t}}\right)^{\rho(1-\alpha)}+1-\delta_{K}-\tau\right]-1,
$$

with $\bar{\tau}$ taken as given, and $C_{0}$ determined simultaneously by

$$
C_{0}=\left[A \tau^{1-\alpha}\left(1+\frac{\bar{\tau} \bar{K}_{0}}{\tau K_{0}}\right)^{\rho(1-\alpha)}-\left(\gamma_{1}+\delta_{K}+\tau\right)\right] K_{0}
$$

and (13). The values of $K_{t}$ and $\bar{K}_{t}$ are determined as the outcome of consumer optimization. Similar expressions apply to the foreign country.

When the governments do not coordinate their choices, each maximizes the welfare of its representative household, ignoring the welfare impact on the other country. The Nash equilibrium choice of tax rates is therefore determined by

$$
\begin{gathered}
\frac{1}{C_{0}} \frac{\partial C_{0}}{\partial \tau}+\sum_{t=0}^{\infty} \beta^{t} \frac{1}{1+\gamma_{t}} \frac{\partial \gamma_{t}}{\partial \tau}=0, \\
\frac{1}{\bar{C}_{0}} \frac{\partial \bar{C}_{0}}{\partial \bar{\tau}}+\sum_{t=0}^{\infty} \beta^{t} \frac{1}{1+\bar{\gamma}_{t}} \frac{\partial \bar{\gamma}_{t}}{\partial \bar{\tau}}=0
\end{gathered}
$$

When the two governments coordinate their choice of policies, the tax rates are chosen simultaneously to maximize the sum of the welfare levels of their representative households, taking into account the spillover effects. The coordinated 
optimization still takes into account the fact that the households choose the paths of capital and these conditions remain the same as in the equilibrium without coordination. The objective for the coordinated choice of policy is defined as

$$
\max _{\{\tau, \bar{\tau}\}_{t=0}^{\infty}} U+\bar{U},
$$

where now the first-order conditions involve

$$
\begin{gathered}
\frac{1}{C_{0}} \frac{\partial C_{0}}{\partial \tau}+\frac{1}{\bar{C}_{0}} \frac{\partial \bar{C}_{0}}{\partial \tau}+\sum_{t=0}^{\infty} \beta^{t} \frac{1}{1+\gamma_{t}} \frac{\partial \gamma_{t}}{\partial \tau}+\sum_{t=0}^{\infty} \beta^{t} \frac{1}{1+\gamma_{t}} \frac{\partial \bar{\gamma}_{t}}{\partial \tau}=0, \\
\frac{1}{C_{0}} \frac{\partial C_{0}}{\partial \bar{\tau}}+\frac{1}{\bar{C}_{0}} \frac{\partial \bar{C}_{0}}{\partial \bar{\tau}}+\sum_{t=0}^{\infty} \beta^{t} \frac{1}{1+\bar{\gamma}_{t}} \frac{\partial \gamma_{t}}{\partial \bar{\tau}}+\sum_{t=0}^{\infty} \beta^{t} \frac{1}{1+\bar{\gamma}_{t}} \frac{\partial \bar{\gamma}_{t}}{\partial \bar{\tau}}=0 .
\end{gathered}
$$

A comparison of (16) and (17) with (14) and (15) illustrates the effect of the externalities in the model. With uncoordinated optimization, each government ignores the effect that its choice of tax rate has upon welfare in the other country. These effects operate through the interaction of the households and directly through the infrastructural spillover. These effects are internalized in the coordinated case, so the two outcomes will differ. The simulation below explores the manner in which they differ.

Now consider the possibility of intervention by a supranational central body with redistribution of tax revenues that are used to finance the public input into production. The interaction between the central body and the national government is modeled as the following multistage game. In the first stage, the central body announces what share of the tax revenues will be collected for the centralized fund from each national government. In the second stage, the governments choose optimal tax rates. In the third stage, the central body announces how the centralized fund will be divided between the two countries. Finally, investments are made and production takes place. There is no coordination between the two national governments at any stage.

The central government takes a fraction $\theta$ of the home government revenue and a fraction $\bar{\theta}$ of the foreign government revenue. After the tax (public investment) decisions are made in each country, it returns fraction $\mu$ of the total collected revenues to the home country and fraction $1-\mu$ to the foreign country. With this system, the budget constraint in the home country is

$$
G_{t}=(1-\theta) \tau K_{t}+\mu \Omega_{t},
$$

where $\Omega_{t}=\theta \tau K_{t}+\bar{\theta} \bar{\tau} \bar{K}_{t}$. Hence, along the balanced growth path,

$$
G_{t}=\left[(1-\theta+\theta \mu) \tau+\bar{\theta} \mu \bar{\tau} \frac{\bar{K}_{t}}{K_{t}}\right] K_{t}=\Upsilon_{t} K_{t},
$$


and, similarly,

$$
\bar{G}_{t}=\left[(1-\bar{\theta}+\bar{\theta}(1-\mu)) \bar{\tau}+\theta(1-\mu) \tau \frac{K_{t}}{\bar{K}_{t}}\right] \bar{K}_{t}=\bar{\Upsilon}_{t} \bar{K}_{t} .
$$

The optimization problems for the households in the home and foreign countries do not change, because they take the government policy variables as given. The optimization problem of the home country government becomes

$$
\max _{\{\tau\}} U=\frac{1}{1-\beta}\left[\ln \left(C_{0}\right)+\sum_{t=0}^{\infty} \beta^{t} \ln \left(1+\gamma_{t}\right)\right],
$$

where

$$
\gamma_{t}=\beta\left[\alpha A \Upsilon_{t}^{1-\alpha}\left(1+\frac{\bar{G}_{t}}{\Upsilon_{t} K_{t}}\right)^{\rho(1-\alpha)}+1-\delta_{K}-\tau\right]-1,
$$

with the tax rate $\bar{\tau}$ and the policy $\{\mu, \theta\}$ taken as given. The first-order condition becomes

$$
\frac{1}{C_{0}} \frac{\partial C_{0}}{\partial \tau}+\sum_{t=0}^{\infty} \beta^{t} \frac{1}{1+\gamma_{t}}\left[\frac{\partial \gamma_{t}}{\partial \Upsilon_{t}} \frac{\partial \Upsilon_{t}}{\partial \tau}+\frac{\partial \gamma_{t}}{\partial \tau}\right]=0
$$

Similarly for the foreign country

$$
\frac{1}{\bar{C}_{0}} \frac{\partial \bar{C}_{0}}{\partial \bar{\tau}}+\sum_{t=0}^{\infty} \beta^{t} \frac{1}{1+\bar{\gamma}_{t}}\left[\frac{\partial \bar{\gamma}_{t}}{\partial \bar{\Upsilon}_{t}} \frac{\partial \bar{\Upsilon}_{t}}{\partial \bar{\tau}}+\frac{\partial \bar{\gamma}_{t}}{\partial \bar{\tau}}\right]=0 .
$$

We now employ a simulation analysis to compare the solutions that emerge for the three equilibrium concepts. The aim of the simulation is to contrast the uncoordinated and the coordinated equilibria and to investigate what can be achieved by intervention. In interpreting the results, it should be observed that there are three potential sources of inefficiency. First, the household in each country chooses a time path for capital given the tax policy. Both households ignore any externalities arising from their choices. Second, the governments can only indirectly influence the choices of the households through the choice of a tax rate. The tax on capital distorts the intertemporal consumption choice. Third, when the governments do not coordinate, they ignore the positive externality from infrastructural spillovers. Coordinating the tax choices of the governments addresses only the third source of inefficiency, so coordination alone will not achieve a first-best outcome.

The simulation adopts the parameter values $\beta=0.9, \rho=0.5, \alpha=0.65$, $\delta_{K}=0.15, A=\bar{A}=1.3$, and $K_{0}=\bar{K}_{0}=2$. Because the parameters are identical for both countries, the equilibrium for the model will be a balanced growth path with the same rate of growth in both countries. The symmetric equilibrium without coordination between countries is illustrated in Figure 2. The 


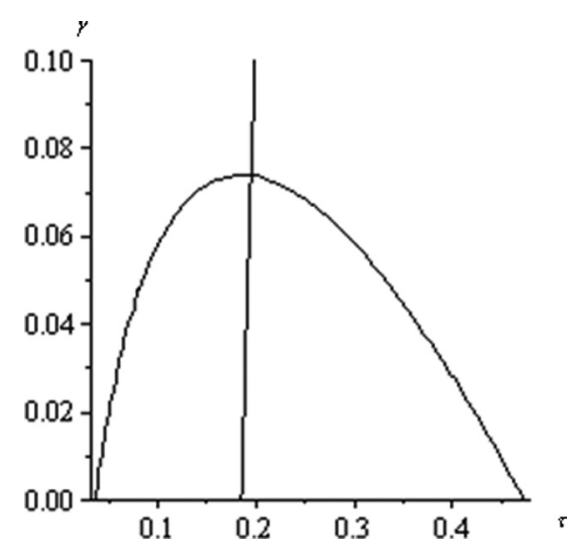

FIGURE 2. Without coordination.

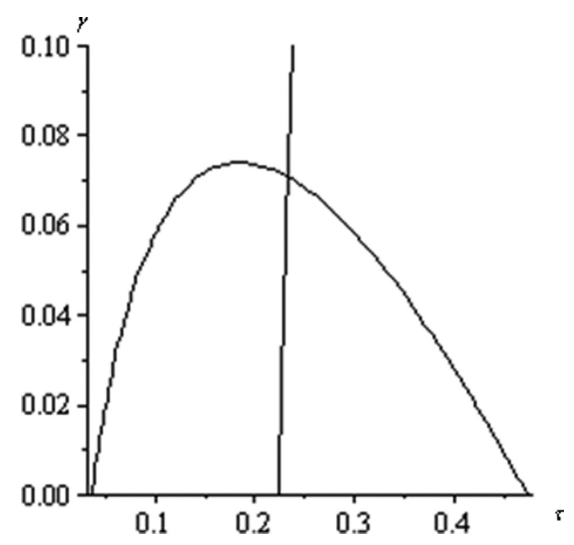

FIGURE 3. Equilibrium with coordination.

equilibrium occurs at the intersection of the two curves determined by (11) and (14). At the equilibrium $\tau_{n}=0.1944, \gamma_{n}=0.0740$ and $U_{n}=4.4693$. As in the single-country case, the chosen tax rate does not maximize the growth rate. (The growth-maximizing tax rate is $\tau_{g}=0.1850$, resulting in $\gamma_{g}=0.0741$ and $U_{g}=4.3197$.) We now proceed to show that this outcome does not maximize welfare either. This is a consequence of the fact that in this equilibrium all three sources of inefficiency are present.

Figure 3 displays the equilibrium with coordinated policy choice for the same values of the model parameters. It can be seen that both the tax rate and the growth rate are higher than in the case without coordination. The values in this case are $\tau_{c}=0.2329, \gamma_{c}=0.0710$, and $U_{c}=4.6026$. The coordination ensures that the infrastructural externality between the governments is internalized, so the third source of inefficiency is removed. The internalization of the externality provides 
TABLE 1. Effect of intervention

\begin{tabular}{lcll}
\hline$\theta$ & $\tau_{s}$ & \multicolumn{1}{c}{$\gamma_{s}$} & $U_{s}$ \\
\hline-1.5 & 0.283 & 0.0623 & 4.344 \\
-1.3 & 0.271 & 0.0674 & 4.448 \\
-1.1 & 0.260 & 0.0670 & 4.528 \\
-0.9 & 0.247 & 0.0689 & 4.579 \\
-0.7 & 0.236 & 0.0706 & 4.602 \\
-0.5 & 0.224 & 0.0720 & 4.593 \\
-0.3 & 0.212 & 0.0731 & 4.550 \\
-0.1 & 0.200 & 0.0738 & 4.469 \\
0 & 0.194 & 0.074 & 4.414 \\
0.1 & 0.188 & 0.0741 & 4.349 \\
\hline
\end{tabular}

the incentive to set a higher tax rate. The growth rate and the welfare level are increased by coordination to the maximum level possible given the financing of infrastructure through a distortionary capital tax.

Table 1 details the effect of intervention for a range of values of $\theta$. Because the countries are symmetric, the optimal value of $\mu=0.5$. The maximum growth rate is achieved by $\theta=0.15$, but this value does not coincide with the value of $\theta=-0.66$ that delivers maximum welfare, $U=U_{c}$, with $\tau=\tau_{c}$ and $\gamma=\gamma_{c}$. Observe, though, that the value of $\theta$ is negative, which represents the central body matching the tax revenues of the individual countries. This is not surprising. We have shown that the equilibrium tax rates are too low in the absence of coordination, because the infrastructural spillover causes a positive externality. Intervention by the central body is needed to raise the tax rates, and this is achieved by a process of revenue-matching. The central body finances this revenue-matching by claiming back revenues (through $\mu$ ) once the tax rates have been determined.

\section{CAPITAL MOBILITY}

A central feature of the EU single market is the free mobility of capital between member states. The literature on tax competition has demonstrated how capital mobility results in inefficiently low tax rates because of the tax externality linking countries. We now wish to investigate the consequences for growth when capital mobility interacts with the infrastructural spillovers that we have been considering.

To do this, we assume that capital is perfectly mobile and can be reallocated between countries costlessly. We also assume that capital is taxed in the country where it is employed. Each consumer will therefore choose to invest in the country where the after-tax return on capital is higher. This imposes an arbitrage condition on the return to capital, so in equilibrium the after-tax return on capital is equalized between countries.

Let $k_{t}$ denote the stock of capital owned by the "home" consumer, $k_{t}^{h}$ the investment in the home country, and $k_{t}^{f}$ the investment in the foreign country. 
Clearly, $k_{t}=k_{t}^{h}+k_{t}^{f}$. The variables $\bar{k}_{t}, \bar{k}_{t}^{h}$, and $\bar{k}_{t}^{f}$ are defined in the same way. Thus the quantity of capital employed in production in the home country at time $t$ is

$$
K_{t}=k_{t}^{h}+\bar{k}_{t}^{h} .
$$

Similarly, for the foreign country

$$
\bar{K}_{t}=k_{t}^{f}+\bar{k}_{t}^{f} .
$$

From (10) and profit maximization, the rental rate of capital in the home country is given by

$$
r_{t}=\alpha A\left[\frac{G_{t}^{1-\rho} \Gamma_{t}^{\rho}}{k_{t}^{h}+\bar{k}_{t}^{h}}\right]^{1-\alpha}-\tau
$$

and in the foreign country by

$$
\bar{r}_{t}=\alpha A\left[\frac{\bar{G}_{t}^{1-\rho} \Gamma_{t}^{\rho}}{k_{t}^{f}+\bar{k}_{t}^{f}}\right]^{1-\alpha}-\bar{\tau} .
$$

Because capital is internationally mobile, the arbitrage condition requires that the rental rates be equalized:

$$
\alpha A\left[\frac{G_{t}^{1-\rho} \Gamma_{t}^{\rho}}{k_{t}^{h}+\bar{k}_{t}^{h}}\right]^{1-\alpha}-\tau=\alpha A\left[\frac{\bar{G}_{t}^{1-\rho} \Gamma_{t}^{\rho}}{k_{t}+\bar{k}_{t}-k_{t}^{h}-\bar{k}_{t}^{h}}\right]^{1-\alpha}-\bar{\tau} .
$$

This arbitrage condition determines $k_{t}^{h}+\bar{k}_{t}^{h}$ given $k_{t}+\bar{k}_{t}$, and hence the world return on capital,

$$
R_{t}=R_{t}\left(k_{t}+\bar{k}_{t}\right)
$$

The wage rate in the home country is given by

$$
w_{t}=[1-\alpha] A\left[k_{t}^{h}+\bar{k}_{t}^{h}\right]^{\alpha}\left[G_{t}^{1-\rho} \Gamma_{t}^{\rho}\right]^{1-\alpha}=W_{t}\left(k_{t}+\bar{k}_{t}\right),
$$

and in the foreign country by

$$
\bar{w}_{t}=[1-\alpha] A\left[k_{t}^{f}+\bar{k}_{t}^{f}\right]^{\alpha}\left[\bar{G}_{t}^{1-\rho} \Gamma_{t}^{\rho}\right]^{1-\alpha}=\bar{W}_{t}\left(k_{t}+\bar{k}_{t}\right) .
$$

The decision problem of the home consumer is to choose the time path of capital holdings $\left\{k_{t}\right\}$ taking as given the prices, $\left\{w_{t}, R_{t}\right\}$, and the tax rates, $\{\tau, \bar{\tau}\}$. Initial capital holdings, $\left\{k_{0}, \bar{k}_{0}\right\}$, are fixed. The arbitrage condition implies that the division of capital between countries does not matter in the intertemporal optimization, so the home consumer solves

$$
\max _{\left\{k_{t}\right\}} U=\sum_{t=0}^{\infty} \beta^{t} \ln \left[w_{t}+R_{t} k_{t}+\left(1-\delta_{K}\right) k_{t}-k_{t+1}\right]
$$


subject to the budget constraint

$$
C_{t}=w_{t}+R_{t} k_{t}+\left(1-\delta_{K}\right) k_{t}-k_{t+1} .
$$

The sequence of first-order conditions for the optimization is

$$
-\frac{1}{C_{t-1}}+\frac{\beta}{C_{t}}\left(1-\delta_{K}+R_{t}\right)=0, \quad t=1,2, \ldots
$$

Using the definition $\gamma_{t} \equiv C_{t} / C_{t-1}$, we write these conditions as

$$
\gamma_{t}=\beta\left[1-\delta_{K}+R_{t}\right]-1, \quad t=1,2, \ldots
$$

The consequence of capital mobility is immediately evident from (24). The arbitrage condition ensures that both consumers face the same rental rate for capital, $R_{t}$, so the right-hand side of (24) is not country-dependent. Hence, the growth rate of consumption must be the same in both countries at every time, $t: \gamma_{t}=\bar{\gamma}_{t}$, $t=1,2, \ldots$. This consequence of perfect mobility has been observed previously by Razin and Yuen (1997). Similar issues have also been addressed by Bianconi and Turnovsky (1997), but in a model that does not have public infrastructure.

Moving to the first stage, the home and foreign tax rates are determined simultaneously in the Nash equilibrium between home and foreign governments. The home government solves

$$
\max _{\{\tau\}} U=\sum_{t=0}^{\infty} \beta^{t} \ln \left(C_{t}\right)
$$

subject to the balanced budget constraint

$$
G_{t}=\tau K_{t}
$$

and (21)-(24). The home government also recognizes that the foreign government runs a balanced budget,

$$
\bar{G}_{t}=\bar{\tau} \bar{K}_{t},
$$

but treats $\bar{\tau}$ as fixed when optimizing. The corresponding equations apply for the foreign consumer and foreign government.

The constancy of $\tau$ and $\bar{\tau}$ implies that the solution of (24) (and the foreign equivalent) will be a balanced growth path with an intertemporally constant world rental rate for capital. We denote the growth rate by $\gamma$ and the rental rate by $R$ and proceed to determine the dependence of these upon the tax rates. The home government's objective is to solve

$$
\max _{\{\tau\}} U=\sum_{t=0}^{\infty} \beta^{t} \ln \left[C_{0}(1+\gamma)^{t}\right]=\frac{1}{1-\beta} \ln \left(C_{0}\right)+\frac{\beta}{(1-\beta)^{2}} \ln (1+\gamma),
$$

where

$$
\gamma=\beta\left[1-\delta_{K}+R\right]-1,
$$


and the world return on capital is determined from the arbitrage condition. On the balanced growth path $k_{t}=(1+\gamma)^{t} k_{0}, \bar{k}_{t}=(1+\gamma)^{t} \bar{k}_{0}$, etc., so the arbitrage condition can be rewritten as

$$
\begin{aligned}
R & =\alpha A \tau^{1-\alpha}\left[1+\frac{\bar{\tau}}{\tau} \frac{k_{0}+\bar{k}_{0}-K_{0}}{K_{0}}\right]^{1-\alpha}-\tau \\
& =\alpha A \bar{\tau}^{1-\alpha}\left[1+\frac{\tau}{\bar{\tau}} \frac{K_{0}}{k_{0}+\bar{k}_{0}-K_{0}}\right]^{1-\alpha}-\bar{\tau}
\end{aligned}
$$

Given the technology parameters and the initial holdings of capital $k_{0}+\bar{k}_{0}$, this equation determines $K_{0}$ and $R$ as a function of just $\tau$ and $\bar{\tau}$. All that remains is to evaluate $C_{0}$, which then completely identifies welfare as a function of the tax rates.

We have

$$
\begin{aligned}
C_{t} & =w_{t}+R k_{t}+\left(1-\delta_{K}\right) k_{t}-k_{t+1} \\
& =(1-\alpha) \frac{Y_{t}}{K_{t}} K_{t}+\alpha \frac{Y_{t}}{K_{t}} k_{t}-\left(\gamma+\delta_{K}+\tau\right) k_{t} .
\end{aligned}
$$

On the balanced growth path (27) implies

$$
\frac{Y_{t}}{K_{t}}=\frac{1}{\alpha}\left(\frac{1+\gamma}{\beta}-1+\delta_{K}+\tau\right) .
$$

Therefore,

$$
C_{0}=\frac{1}{\alpha}\left(\frac{1+\gamma}{\beta}-1+\delta_{K}+\tau\right)\left[(1-\alpha) K_{0}+\alpha k_{0}\right]-\left(\gamma+\delta_{K}+\tau\right) k_{0},
$$

where

$$
\gamma=-1+\beta\left[1-\delta_{K}-\tau+\alpha A \tau^{1-\alpha}\left(1+\frac{\tau}{\bar{\tau}} \frac{K_{0}}{k_{0}+\bar{k}_{0}-K_{0}}\right)^{\rho(1-\alpha)}\right] .
$$

The first-order condition for the home government's optimization problem when there is no coordination can now be written as

$$
\begin{gathered}
\frac{d U}{d \tau}=\frac{1}{1-\beta} \frac{1}{C_{0}}\left[\frac{\partial C_{0}}{\partial \tau}+\frac{\partial C_{0}}{\partial \gamma} \frac{\partial \gamma}{\partial \tau}+\frac{\partial C_{0}}{\partial K_{0}} \frac{\partial K_{0}}{\partial \tau}\right] \\
+\frac{\beta}{(1-\beta)^{2}} \frac{1}{1+\gamma}\left[\frac{\partial \gamma}{\partial \tau}+\frac{\partial \gamma}{\partial K_{0}} \frac{\partial K_{0}}{\partial \tau}\right]=0,
\end{gathered}
$$

where $\partial K_{0} / \partial \tau$ is found by taking the total differential of the arbitrage condition (28). The pair of Nash equilibrium taxes is found by solving this equation simultaneously with the analogous equation for the foreign government. 
TABLE 2. Equilibrium with mobile capital

\begin{tabular}{lcc}
\hline \multicolumn{3}{c}{ Without coordination } \\
\hline$\tau_{n}$ & $\gamma_{n}$ & $U_{n}$ \\
\hline 0.162 & 0.0732 & 3.901 \\
& With coordination & \\
\hline$\tau_{c}$ & $\gamma_{c}$ & $U_{c}$ \\
\hline 0.2329 & 0.0710 & 4.6026 \\
\hline
\end{tabular}

With coordination the two governments choose the two tax rates to maximize the sum of welfare levels,

$$
\begin{aligned}
& \frac{d(U+\bar{U})}{d \tau}=0, \\
& \frac{d(U+\bar{U})}{d \bar{\tau}}=0 .
\end{aligned}
$$

With intervention of a supranational body, in the form of redistribution of tax revenues, as in the situation with immobile capital considered in the previous section, the tax rates in the government budget constraints are replaced by the effective tax rates

$$
G_{t}=\Upsilon K_{t},
$$

where $\Upsilon \equiv(1-\theta+\theta \mu) \tau+\bar{\theta} \mu \bar{\tau} \frac{\bar{K}_{t}}{K_{t}}$.

The results of simulating the model with our standard parameter values are summarized in Table 2. Without coordination the tax rate is below the rate with immobile capital, which is a consequence of the tax competition induced by the mobility of capital. As a result, the growth rate and the welfare level are both smaller than those achieved with immobile capital. Coordination between the countries succeeds in internalizing the externality arising from the mobility of capital and achieves exactly the same outcome as in the economy with immobile capital.

Table 3 details the outcome obtained with a supranational body redistributing tax revenues between governments. The redistribution policy achieves the coordinated outcome when $\theta=-1.55$. The supranational body is therefore able to internalize the externality from capital mobility and address the externality from the infrastructural spillover. To achieve this the degree of intervention, as measured by the value of the revenue-matching parameter $\theta$, has to be greater with mobile capital than with immobile capital. 
TABLE 3. Coordination with capital mobility

\begin{tabular}{lccc}
\hline$\theta$ & $\tau_{s}$ & $\gamma_{s}$ & $U_{s}$ \\
\hline-1.7 & 0.286 & 0.0615 & 4.308 \\
-1.5 & 0.225 & 0.0719 & 4.595 \\
-1.3 & 0.202 & 0.0737 & 4.489 \\
-1.1 & 0.190 & 0.0741 & 4.362 \\
-0.9 & 0.181 & 0.0741 & 4.249 \\
-0.7 & 0.175 & 0.0740 & 4.150 \\
-0.5 & 0.170 & 0.0738 & 4.066 \\
-0.3 & 0.166 & 0.0736 & 3.993 \\
-0.1 & 0.163 & 0.0733 & 3.930 \\
0 & 0.162 & 0.0732 & 3.501 \\
0.1 & 0.161 & 0.0731 & 3.874 \\
\hline
\end{tabular}

\section{CONCLUSIONS}

We have analyzed economies in which public sector expenditure is productive and there are spillovers of the benefit of public infrastructure between countries. An increase in infrastructure in one country raises the growth rate in all countries, which creates an externality between countries. If the choices of individual countries are not coordinated, then the externality effect will result in an inefficient choice of policy and the resulting growth rate will not be welfare-maximizing. Capital mobility creates a second externality, and the inefficiency is made worse through tax competition.

The policy implications of our analysis are that although public expenditure can assist growth, there is no guarantee that the optimal rate of growth will be achieved. The design of the public expenditure program has to take into account the infrastructural spillovers between countries and the mobility of the tax base. A coordinating body, such as the EU, has a role to play in attaining a more efficient level of taxation and expenditure on public infrastructure. This role involves inducing individual countries to raise tax rates through revenue matching, which raises the overall level of expenditure on infrastructure. However, this intervention will not achieve the first best if the tax instrument is distortionary.

It can be argued that empirical data show only a weak relationship between taxation and economic growth [see Myles (2007) for a survey of the literature]. Both capital mobility and infrastructural externalities have the effect of reducing growth differentials between countries (and completely eliminating the differential when capital is perfectly mobile). These effects will not be apparent in crosscountry comparisons taken at one point, which may help explain the lack of a relationship in the data. 


\section{NOTE}

1. The alternative of the public good as a stock is modeled in Hashimzade and Myles (2009), but the paper contrasts balanced growth paths, so it does not consider transition issues.

\section{REFERENCES}

Barro, Robert J. (1990) Government spending in a simple model of endogenous growth. Journal of Political Economy 98, S103-S125.

Becker, Daniel and Michael Rauscher (2007) Fiscal Competition in Space and Time: An EndogenousGrowth Approach. CESifo Working Paper 2048.

Bianconi, Marcelo and Stephen J. Turnovsky (1997) International effects of government expenditure in interdependent economies. Canadian Journal of Economics 30, 57-84.

Boadway, Robin and Anwar Shah (2009) Fiscal Federalism: Principles and Practice of Multi-Order Governance. Cambridge, UK: Cambridge University Press.

Brueckner, Jan K. (2006) Fiscal federalism and economic growth. Journal of Public Economics 90, 2107-2120.

Chen, Jhy-hwa, Jhy-yuan Shieh, Ching-chong Lai, and Juin-jen Chang (2005) Productive public expenditure and imperfect competition with endogenous price markup. Oxford Economic Papers $47,522-544$.

Cooley, Thomas F. and Edward C. Prescott (1995) Economic growth and business cycles. In Thomas F. Cooley (ed.), Frontiers of Business Cycle Research, pp. 1-38. Princeton, NJ: Princeton University Press.

Futagami, Koichi, Yuichi Morita, and Akihisa Shibata (1993) Dynamic analysis of an endogenous growth model with public capital. Scandinavian Journal of Economics 95, 607-625.

Gomez, Manuel A. (2004) Optimal fiscal policy in a growing economy with public capital. Macroeconomic Dynamics 8, 419-435.

Hashimzade, Nigar and Gareth D. Myles (2009) Growth and Public Infrastructure. Economics and Management Discussion Papers 2009-03, Henley Business School, University of Reading.

Hatfield, John W. (2006) Federalism, Taxation, and Economic Growth. Research Papers 1929, Graduate School of Business, Stanford University.

Irmen, Andreas and Johanna Kuehnel (2009) Productive government expenditure and economic growth. Journal of Economic Surveys 23, 692-733.

Iwamoto, Yasushi and Akihisa Shibata (2008) International and intergenerational aspects of capital income taxation in an endogenously growing world economy. Review of International Economics $16,383-399$

Marrero, Gustavo A. (2008) Revisiting the optimal stationary public investment policy in endogenous growth economies. Macroeconomic Dynamics 12, 172-194.

Myles, Gareth D. (2007) Economic Growth and the Role of Taxation. OECD.

Rauscher, Michael (2005) Economic growth and tax-competing leviathans. International Tax and Public Finance 12, 457-474.

Razin, Assaf and Chi-Wa Yuen (1997) Factor mobility and income growth: two convergence hypotheses. Review of Development Economics 1, 171-190.

Tsoukis, Chris and Nigel J. Miller (2003) Public services and endogenous growth. Journal of Policy Modeling 25, 297-307.

Turnovsky, Stephen J. (1999) Productive government expenditure in a stochastically growing economy. Macroeconomic Dynamics 3, 544-570.

Turnovsky, Stephen J. (2004) The transitional dynamics of fiscal policy: Long-run capital accumulation and growth. Journal of Money, Credit and Banking 36, 883-910. 